\title{
Glutathione metabolism in cultured Sertoli cells and spermatogenic cells from hamsters
}

\author{
P. J. Den Boer, P. Mackenbach and J. A. Grootegoed \\ Department of Biochemistry II, Medical Faculty, Erasmus University Rotterdam, P.O. Box 1738, \\ 3000 DR Rotterdam, The Netherlands
}

\begin{abstract}
Summary. Isolated spermatocytes and spermatids from hamsters contained a large amount of glutathione (GSH) ( $\sim 40$ and $30 \mathrm{nmol} \mathrm{GSH} / \mathrm{mg}$ protein, respectively), but showed a spontaneous decrease of GSH content during prolonged incubation $\left(t_{1 / 2}\right.$ $\sim 35 \mathrm{~h}$ ). Incubation of the germ cells in the presence of the glutathione biosynthesis inhibitor buthionine sulphoximine (BSO) provided evidence that the cells can perform glutathione synthesis. This synthesis, however, was not sufficient to maintain the GSH content of the isolated cells, or to restore the cellular GSH pool after depletion caused by exposure of the cells to the glutathione $S$-transferase substrate, diethyl maleate (DEM). Cultured Sertoli cells, containing $\sim 10 \mathrm{nmol} \mathrm{GSH} / \mathrm{mg}$ protein, had a more active BSO-sensitive GSH synthesis system. The Sertoli cells, but also tubule fragments containing Sertoli cells and germ cells, were able to restore their GSH pool after DEMinduced depletion. DEM treatment of the tubule fragments resulted in a $90 \%$ decrease of the GSH content of the spermatocytes and spermatids present within the fragments. The GSH levels of the tubule fragments and the enclosed germ cells were restored during a subsequent incubation in the absence of DEM. As indicated above, such a recovery was not observed for isolated spermatocytes and spermatids. The results illustrate the importance of Sertoli cell-germ cell interaction, and point to a role of Sertoli cells in glutathione synthesis by the germ cells.
\end{abstract}

Keywords: glutathione; testis; Sertoli cells; spermatocytes; spermatids; hamster

\section{Introduction}

Glutathione (the tripeptide L- $\gamma$-glutamyl-L-cysteinylglycine) is the most abundant non-protein thiol in mammalian cells. Reduced glutathione (GSH), with a free sulphydryl group, is involved in many biological processes, including synthesis of proteins and DNA, transport of amino acids and protection of cells against oxidation (Meister \& Anderson, 1983). High concentrations of GSH have been found in rat and mouse testes (Calvin \& Turner, 1982; Grosshans \& Calvin, 1985). The concentration of GSH in rat testis ( $\mu \mathrm{mol} / \mathrm{g}$ tissue) increases approximately 3-fold between Days 8 and 29 of post-natal development, coinciding with the onset of spermatogenesis, and is then maintained at a high level during further testicular development (Calvin \& Turner, 1982). However, there is little information about the role and the metabolism of glutathione in Sertoli cells and spermatogenic cells.

Testicular glutathione levels can be reduced in immature mice (Calvin et al., 1986) and, to a lesser extent, also in mature rats (Teaf et al., 1987), by treatment of the animals with buthionine sulphoximine (BSO), which is a specific inhibitor of GSH synthesis (Griffith \& Meister, 1979). However, these studies do not provide evidence that the testis can perform glutathione synthesis, and do not give information on the ability of the different testicular cell types to synthesize GSH. 
In studies using isolated round spermatids from rats, it has been shown that the germ cells were partly depleted of glutathione after incubation with diethyl maleate (Den Boer et al., 1988). This compound is a glutathione S-transferase substrate. There are a number of glutathione S-transferases (EC 2.5.1.18) which catalyse the reaction of GSH with a variety of substrates (Ketterer, 1986). The reaction of GSH with diethyl maleate leads to the formation of a conjugate, resulting in a loss of GSH from the cells.

In the present experiments, isolated spermatocytes, spermatids, Sertoli cells and tubule fragments from hamsters were used to study different aspects of testicular GSH metabolism in more detail. Hamsters were used since earlier studies indicated that isolated cells and tubular fragments indicated from hamsters are suitable model systems (Den Boer \& Grootegoed, 1988a, b).

\section{Materials and Methods}

Isolation and incubation of tubule fragments. Immature 25-26-day-old hamsters (Mesocricetus auratus) were killed by cervical dislocation and the testes were removed. Tubule fragments were isolated by collagenase treatment as described by Den Boer \& Grootegoed (1988b). The tubule fragments contained Sertoli cells and spermatogenic cells, and this preparation was also referred to as spermatogenic epithelium. The tubule fragments were incubated in Eagle's minimum essential medium (MEM) containing Earle's salts and $25 \mathrm{mM}$-Hepes (Gibco, Paisley, UK) supplemented with antibiotics (Grootegoed et al., 1985), L-glutamine $(292 \mathrm{mg} / \mathrm{l})$ and $\mathrm{l} \%$ fetal calf serum (FCS). The incubations were performed for 24,48 or $72 \mathrm{~h}$ at $32^{\circ} \mathrm{C}$ under an atmosphere of $5 \% \mathrm{CO}_{2}$ in air, using 12-well plates or $150 \mathrm{~cm}^{2}$ $(650 \mathrm{ml})$ tissue-culture flasks (Costar, Broadway, Cambridge, MA, USA), with $\sim 200 \mu \mathrm{g}$ cellular protein $/ \mathrm{cm}^{2}$. From each sample the amounts of protein and GSH were estimated.

Isolation and incubation of spermatocytes and spermatids. Round spermatids and pachytene spermatocytes from 32-35-day-old hamsters were isolated by sedimentation at unit gravity and further purified by Percoll density centrifugation (Den Boer \& Grootegoed, 1988a). The incubations were performed using Dulbecco's phosphate-buffered saline, containing $12 \mathrm{~mm}$-DL-lactate and $0.1 \%$ bovine serum albumin (BSA) (Fraction V: Sigma Chemical Company, St Louis, MO, USA), referred to as PBS-L. Approximately $0.3 \times 10^{6}$ cells were incubated in $0.25 \mathrm{ml}$ PBS-L, in polystyrene tubes (diameter $11.5 \mathrm{~mm}$ ), at $32^{\circ} \mathrm{C}$ in air.

In another series of experiments, round spermatids and pachytene spermatocytes were isolated from tubule fragments, not only immediately after the preparation of the tubules using collagenase, but also after 24 and $72 \mathrm{~h}$ of culture of the tubule fragments. The methods used for this procedure were as described above.

Isolation and incubation of Sertoli cells. Sertoli cells were isolated from 25-day-old hamsters, using the method for isolation of rat Sertoli cells described by Oonk et al. (1985). The cells were cultured in MEM (Gibco, Grand Island, NY, USA), supplemented with non-essential amino acids, glutamine, antibiotics and $1 \% \mathrm{FCS}$ at $32^{\circ} \mathrm{C}$ for $48 \mathrm{~h}$. This incubation was followed by hypotonic shock, to remove most of the germinal cells (Galdieri et al., 1981), and an additional incubation period of $24 \mathrm{~h}$ at $32^{\circ} \mathrm{C}$. Subsequently, the cells were washed and incubated in MEM containing $0.1 \%$ BSA, in the absence of FCS. Effects of different compounds on GSH metabolism were estimated during incubations for 2 and $48 \mathrm{~h}$ at $32^{\circ} \mathrm{C}$ under an atmosphere of $5 \% \mathrm{CO}_{2}$ in air, in a final volume of $2 \mathrm{ml}$ in 12-well plates (Costar) with $\sim 0.12 \mathrm{mg}$ protein $/$ well.

Fluorometric method for determination of reduced glutathione. Determination of cellular GSH content was performed according to the method of Hissin \& Hilf (1976) and Grosshans \& Calvin (1985), with some slight modifications. Sertoli cells and tubule fragments were detached from the wells mechanically, pooled and centrifuged for $5 \mathrm{~min}$ at $600 \mathrm{~g}$. The incubated germ cells in the tubes were not attached and were collected by centrifugation $(5 \mathrm{~min}$ at $600 \mathrm{~g}$ ). The supernatants were discarded and the pellets were frozen and stored at $-80^{\circ} \mathrm{C}$. For glutathione estimation, the cells were lysed in $100-500 \mu \mathrm{l}$ water, and protein was precipitated by adding $50-250 \mu 13 \mathrm{M}$-perchloric acid containing $1 \mathrm{~mm}$-EDTA. The mixture was kept on ice for $10 \mathrm{~min}$, and the precipitated protein was removed by centrifugation. The supernatant was neutralized by addition of $2 \mathrm{M}-\mathrm{KOH} / 0 \cdot 3 \mathrm{M}-\mathrm{Hepes}$, followed by centrifugation to remove $\mathrm{KClO}_{4}$. The final GSH-assay mixture $(500 \mu \mathrm{l})$ contained $25 \mu \mathrm{l}$ of the neutralized supernatant, $450 \mu \mathrm{l}$ of a sodium-phosphate buffer $(0.1 \mathrm{M}$-sodium phosphate, $5 \mathrm{~mm}$-EDTA, $\mathrm{pH} 8.0)$ and $25 \mu \mathrm{l}$ of a solution of $o$-phthaldialdehyde (Sigma) in methanol $(\mathrm{I} \mathrm{mg} / \mathrm{ml})$. After mixing and incubation for $15 \mathrm{~min}$ at room temperature, the fluorescence was determined using a fluorescence spectrophotometer (Kontron Instruments, SFM 25) at $420 \mathrm{~nm}$ (excitation at $350 \mathrm{~nm}$ ).

Estimation of cellular ATP content. The cellular ATP content of the spermatocytes and spermatids was estimated with the bioluminescent firefly luciferin-luciferase reaction (Lumac) as described by Grootegoed et al. (1984), using a model 6100 Pico-Lite Luminometer (Packard).

Estimation of cellular protein. The amount of cellular protein was estimated according to Bradford (1976), using bovine serum albumin as standard. 


\section{Results}

\section{GSH depletion of isolated round spermatids by DEM}

The GSH and ATP contents of the isolated spermatids were estimated at different times during $48 \mathrm{~h}$ of incubation. Freshly isolated spermatids contained $\sim 3 \mathrm{nmol} \mathrm{GSH} / 10^{6} \mathrm{cells}(\sim 30 \mathrm{nmol} / \mathrm{mg}$ protein). The results presented in Fig. 1 show that there was a gradual decrease, during the incubation, of the cellular GSH content $\left(t_{1 / 2} \sim 35 \mathrm{~h}\right)$. This decrease of GSH, however, was not accompanied by a decrease of the ATP content. After the addition of diethyl maleate to the incubations, the cellular GSH pool was depleted within $2 \mathrm{~h}$ (Fig. 1). Subsequently, the cells were washed to remove the diethyl maleate and the incubations were continued in the absence of this compound for $46 \mathrm{~h}$. There was no recovery of the GSH content during this $46-\mathrm{h}$ incubation period. Furthermore, there was no pronounced effect of GSH depletion on the cellular ATP content.

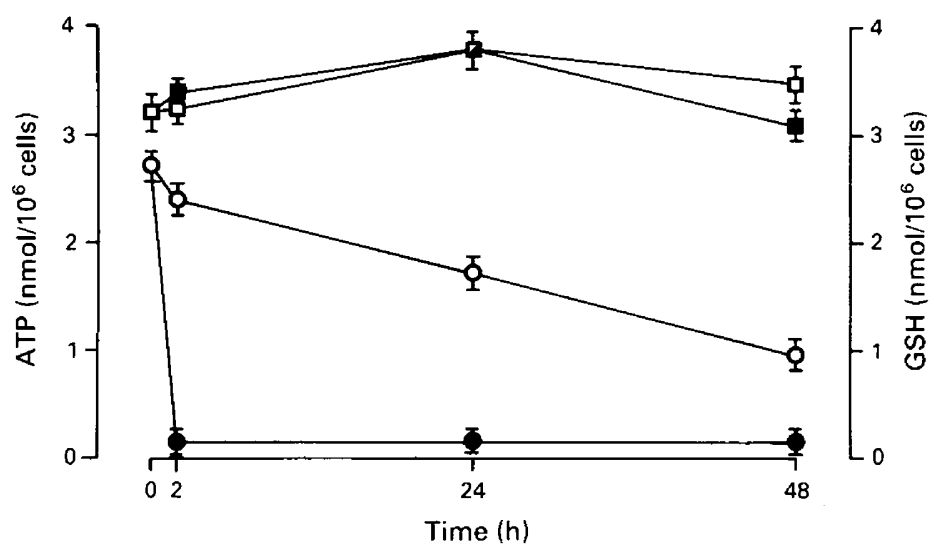

Fig. 1. ATP and GSH contents of GSH-depleted $(\mathbf{Q}, 0)$ and control $(\square, \bigcirc)$ spermatids during incubation for $48 \mathrm{~h}$. The isolated spermatids were depleted of GSH by treatment with $100 \mu \mathrm{M}-$ diethyl maleate (DEM) for $2 \mathrm{~h}$, followed by washing and incubation in the absence of DEM. The control cells were not incubated with DEM, but were also washed after $2 \mathrm{~h}$. At the end of the incubations the cellular $\operatorname{ATP}(\square, \square)$ and $\operatorname{GSH}(\bullet, O)$ contents were estimated. Values are the mean \pm s.d. of triplicate incubations.

Using MEM (containing $1 \mathrm{mM}$-glucose and $12 \mathrm{mM}$-DL-lactate) instead of PBS-L, the cellular GSH pool also showed a gradual decrease during incubation and no recovery after treatment with diethyl maleate (not shown). Addition of L-2-oxothiazolidine-4-carboxylate (10 mM), a compound which commonly can be taken up by cells and intracellularly converted to cysteine, or addition of GSH $(0.1 \mathrm{~mm})$ to the medium also did not result in maintenance or recovery of the glutathione content of the isolated spermatids (not shown).

\section{Effect of BSO on GSH levels in spermatids}

The isolated spermatids were incubated for $42 \mathrm{~h}$ in the absence or presence of $50 \mu \mathrm{M} \mathrm{BSO}$, a specific inhibitor of GSH synthesis. The cellular GSH content of the spermatids was decreased $50 \%$ after $32 \mathrm{~h}$ or $21 \mathrm{~h}$, in the absence or presence of BSO, respectively (Fig. 2). From this result it can be concluded that the spermatids have a low, but noticeable, rate of GSH synthesis.

The ATP content of spermatids incubated for $18 \mathrm{~h}$ in the presence of high BSO concentrations (up to $4 \mathrm{~mm}$ ) was not affected by the inhibitor (Fig. 3), indicating that the observed effect of $50 \mu \mathrm{M}$-BSO on the depletion of the cellular GSH pool was not caused by a non-specific toxic effect of this compound. 


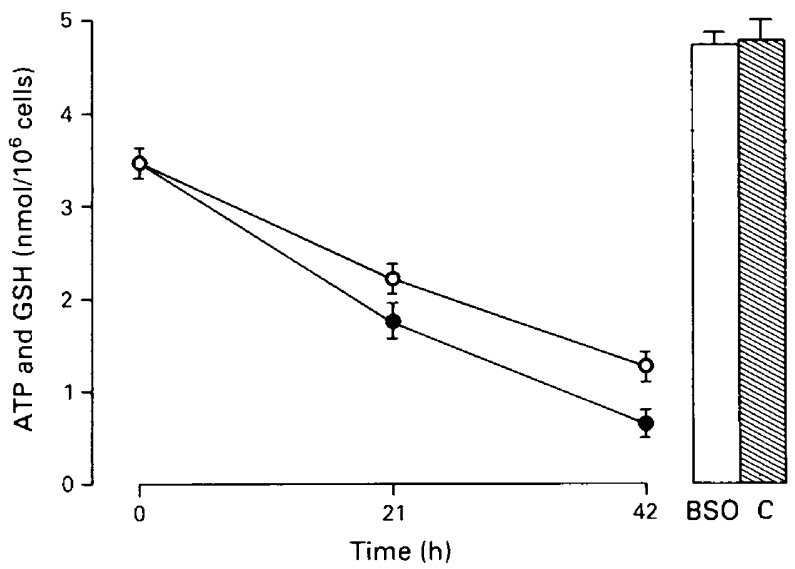

Fig. 2. Effect of BSO on the GSH and ATP contents of isolated spermatids. The lines represent the GSH content of the cells incubated in the absence $(\mathrm{O}-\mathrm{O})$ or presence $(-\longrightarrow)$ of $50 \mu \mathrm{M}$-BSO for 21 and $42 \mathrm{~h}$. The bars represent the ATP values after $42 \mathrm{~h}$ of incubation in the presence $(\square)$ and absence ( $\mathbb{N}$ ) of BSO. The ATP content at the start of the incubation was $4.52 \pm 0.40 \mathrm{nmol} / 10^{6}$ cells. Values are the mean \pm s.d. of triplicate incubations.

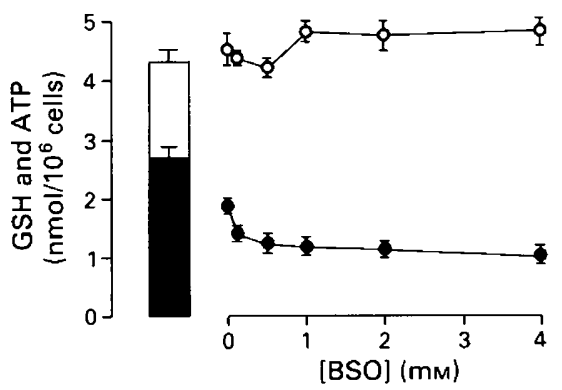

Fig. 3. Effect of different concentrations of BSO on the ATP $\left(\mathrm{O}_{-}\right)$) and GSH ( content of round spermatids. The cells were incubated for $18 \mathrm{~h}$ in the presence of BSO. The bars represent the ATP ( $\square$ ) and GSH ( $\square$ ) content at the start of the incubations. Values are the mean \pm s.d. of triplicate incubations.

\section{Effect of diethyl maleate and BSO on the GSH content of isolated pachytene spermatocytes}

Freshly isolated late pachytene spermatocytes contained $\sim 12 \mathrm{nmol} \mathrm{GSH} / 10^{6}$ cells $(\sim 40 \mathrm{nmol} /$ mg protein). The spermatocytes became depleted of GSH during $2 \mathrm{~h}$ of incubation in the presence of $100 \mu \mathrm{M}$ diethyl maleate. The GSH content of the isolated cells was decreased from $12 \cdot 1 \pm 0 \cdot 9 \mathrm{nmol} / 10^{6}$ cells in the control cells to $0 \cdot 7 \pm 0 \cdot 1 \mathrm{nmol} / 10^{6}$ cells in the treated cells. This level remained low after washing and an additional incubation for $22 \mathrm{~h}$ in the absence of diethyl maleate $\left(0.06 \pm 0.02 \mathrm{nmol} \mathrm{GSH} / 10^{6}\right.$ cells). The GSH content of the isolated spermatocytes, estimated after a $24-\mathrm{h}$ incubation period in the absence or presence of $50 \mu \mathrm{M}$-BSO, was $8 \cdot 2 \pm 0 \cdot 1$ or $6.2 \pm 0.7 \mathrm{nmol} / 10^{6}$ cells, respectively. The isolated spermatocytes, in common with spermatids, did not maintain their GSH content during prolonged incubation. Furthermore, the slightly lower GSH content of the BSO-treated spermatocytes indicates that these cells have a low rate of GSH synthesis, as described above for spermatids. The diethyl maleate and BSO treatments of the spermatocytes did not affect the ATP content of the cells. 


\section{GSH in Sertoli cells}

The metabolism of GSH by cultured Sertoli cells was different from that by the isolated spermatids and spermatocytes. First, the glutathione content of Sertoli cells was $\sim 10 \mathrm{nmol} / \mathrm{mg}$ protein, which is appreciably lower than that of freshly isolated spermatogenic cells. The possible changes of the GSH content of the Sertoli cells during the first 3 days of culture, however, were not studied. Second, after a 2-h exposure of the Sertoli cells to $100 \mu \mathrm{M}$-diethyl maleate the cellular GSH pool was largely depleted, but this pool almost completely recovered when the treated Sertoli cells were washed and incubated for $48 \mathrm{~h}$ in fresh medium (Table 1). Such a recovery was not observed when BSO was added during the incubation period after the diethyl maleate treatment, indicating that the recovery of the GSH pool was dependent on GSH synthesis. Sertoli cells may have a relatively high rate of GSH synthesis, as shown also by the pronounced effect of BSO on the GSH content of Sertoli cells during $2 \mathrm{~h}$ of incubation (Table 1). Under the present incubation conditions there was no loss of protein from the cells (Table 1).

Table 1. Recovery of the glutathione content of hamster Sertoli cells after treatment with diethyl maleate (DEM)

\begin{tabular}{clcc}
\hline $\begin{array}{c}\text { Time } \\
(\mathrm{h})\end{array}$ & \multicolumn{1}{c}{ Treatment } & $\begin{array}{c}\text { GSH } \\
\text { (nmol/mg protein) }\end{array}$ & $\begin{array}{c}\text { Protein } \\
(\mu \mathrm{g} / \text { well) }\end{array}$ \\
\hline 0 & Control & $11 \cdot 9 \pm 1 \cdot 2$ & $130 \pm 12$ \\
2 & Control & $10 \cdot 4 \pm 0 \cdot 9$ & $112 \pm 17$ \\
2 & DEM & $2 \cdot 9 \pm 0 \cdot 1$ & $124 \pm 28$ \\
2 & BSO & $6 \cdot 7 \pm 0 \cdot 5$ & $134 \pm 25$ \\
48 & Control & $10 \cdot 3 \pm 0 \cdot 8$ & $117 \pm 13$ \\
48 & DEM $(0-2 \mathrm{~h})$ & $8 \cdot 1 \pm 0 \cdot 4$ & $111 \pm 15$ \\
48 & DEM $(0-2 \mathrm{~h})$, BSO $(2-48 \mathrm{~h})$ & $1 \cdot 4 \pm 0 \cdot 6$ & $122 \pm 6$ \\
48 & BSO $(048 \mathrm{~h})$ & $0 \cdot 9 \pm 0 \cdot 3$ & $129 \pm 15$ \\
\hline
\end{tabular}

The Sertoli cells were cultured for 3 days, as described in 'Methods'. Subsequently, the incubations were continued for $2 \mathrm{~h}$ or $48 \mathrm{~h}$ in the presence or absence of $100 \mu \mathrm{M}-\mathrm{DEM}$ and $4 \mathrm{~mm}-\mathrm{BSO}$, as indicated. Values are the mean \pm s.d. of quadruplicate incubations.

\section{Depletion and recovery of GSH in spermatocytes and spermatids in tubule fragments}

The possible role of Sertoli cells in the GSH metabolism of spermatogenic cells was studied using various experimental approaches.

First, GSH-depleted (using a 2-h DEM treatment) and control spermatids were incubated for $48 \mathrm{~h}$ in Sertoli cell-conditioned medium, which was collected from Sertoli cells cultured for $24 \mathrm{~h}$ in PBS containing $1 \mathrm{~mm}$-glucose. The conditioned medium was supplemented with $0 \cdot 1 \%$ BSA and 12 mM-DL-lactate. The GSH content, and also the ATP content, of the spermatids incubated in this medium, were not significantly different from the GSH contents of spermatids incubated for $48 \mathrm{~h}$ in PBS-L (not shown). However, it cannot be excluded that the presence of metabolic waste products in the conditioned medium may suppress possible favourable effects of nutrients and secretory cell products on the spermatogenic cells.

Second, GSH-depleted and control spermatids were added to a monolayer of Sertoli cells which had been cultured for 3 days. The spermatids were added to this monolayer in PBS-L supplemented with $1 \mathrm{~mm}$-glucose or MEM containing $12 \mathrm{mM}-\mathrm{DL}-$ lactate and $1 \mathrm{mM}$-glucose. These recombinanttypes of co-culture experiments, however, were not successful. The survival of GSH-depleted and control spermatids was very poor, as compared with the survival of spermatids which were 
incubated in the absence of Sertoli cells (not shown). This was indicated by the low ATP content of the spermatids in the co-culture experiments, which was only $5-10 \%$ of the ATP content of spermatids incubated in PBS-L.

Third, in a more elaborate approach, tubule fragments containing Sertoli cells and spermatogenic cells were used. The fragments were isolated and cultured for $24-72 \mathrm{~h}$, and the effects of BSO and diethyl maleate on the depletion and recovery of the GSH content of the tubule fragments during this culture period were studied. In this series of experiments, a preincubation period of $24 \mathrm{~h}$ was used, during which a $30-40 \%$ decrease (expressed as $\mathrm{nmol} / \mathrm{mg}$ protein) of the GSH pool of the fragments was observed (not shown). After this preincubation period, the GSH content of the tubule fragments remained virtually constant.

In the experiment shown in Fig. 4(a), the preincubated tubule fragments were incubated for 2, 24 and $48 \mathrm{~h}$ in the continuous presence of diethyl maleate or BSO. Exposure to diethyl maleate resulted in a rapid GSH depletion of the tubule fragments, and inhibition of GSH synthesis by BSO caused a gradual decrease of the GSH content. The data in Fig. 4(b) represent a parallel experiment, in which diethyl maleate was removed after $2 \mathrm{~h}$ by washing, followed by incubation in the presence or absence of BSO. In the absence of BSO, the GSH content of the tubule fragments increased. This recovery of the GSH content of the tubule fragments was inhibited by BSO, indicating its dependence on GSH synthesis (Fig. 4b).

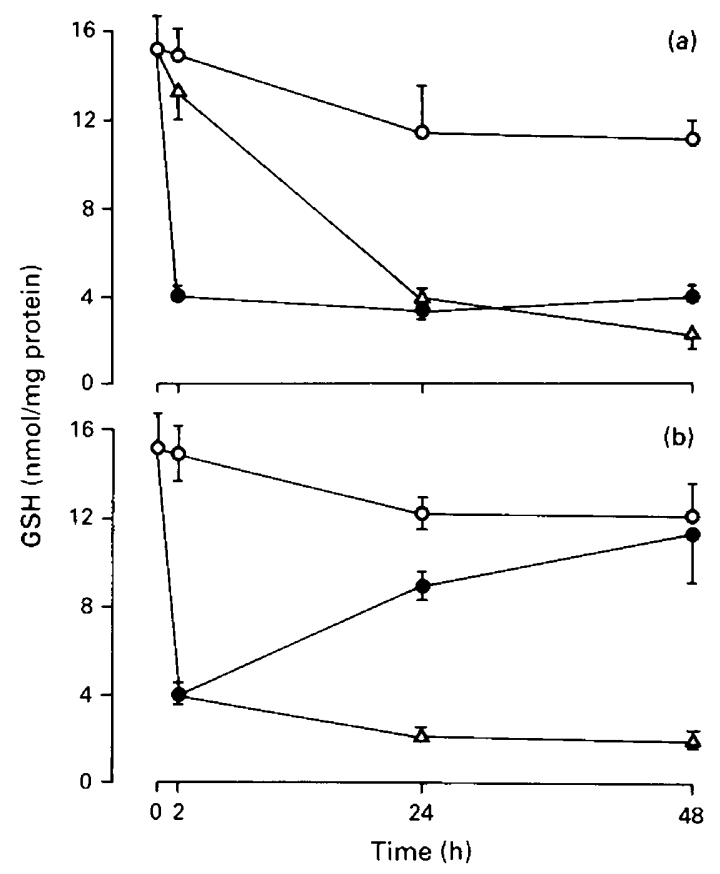

Fig. 4. Effects of DEM and BSO on the GSH content of tubule fragments. The tubule fragments were isolated and preincubated for $24 \mathrm{~h}$ to allow the fragments to attach to the plastic. In (a), the tubule fragments were incubated for $48 \mathrm{~h}$ in the continuous absence $(\mathrm{O}-\mathrm{O})$ or presence of $100 \mu \mathrm{M}-\mathrm{DEM}(--)$ ) or $4 \mathrm{mM}-\mathrm{BSO}(\triangle-\triangle)$. In (b), the tubule fragments were exposed for $2 \mathrm{~h}$ to $100 \mu \mathrm{M}$-DEM, followed by washing and incubation for $46 \mathrm{~h}$ in the absence $(-$ ) or presence of $4 \mathrm{~mm}$-BSO $(\triangle \longrightarrow \triangle)$. The control tubule fragments were not exposed to DEM or BSO $(\mathrm{O}-\mathrm{O})$. Values are the mean \pm s.d. of triplicate incubations. 
Subsequently, it was studied whether spermatogenic cells present within the cultured tubule fragments could maintain and recover their GSH content. Pachytene spermatocytes and round spermatids were isolated from tubule fragments (see 'Methods') after incubation of the fragments under different conditions. After the 24 -h preincubation period, the GSH content of the spermatocytes and spermatids was decreased $50 \%$ as compared with the GSH content of germ cells isolated at the start of the preincubation period (Fig. 5). This decrease correlated with the loss of GSH from the tubule fragments during the 24 -h preincubation period.

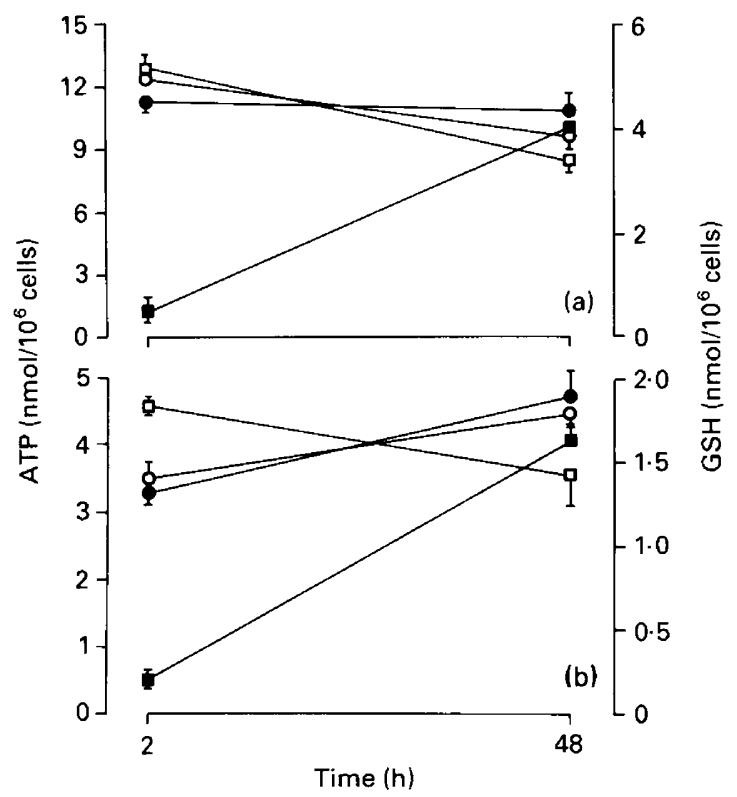

Fig. 5. ATP and GSH contents of (a) spermatocytes and (b) spermatids isolated from DEMtreated tubule fragments. Isolated and preincubated tubule fragments were treated for $2 \mathrm{~h}$ with $100 \mu \mathrm{M}-\mathrm{DEM}$, followed by washing and incubation for $46 \mathrm{~h}$ in the absence of DEM. Germ cells were isolated from control tubule fragments $(O, \square)$ and from DEM-treated tubule fragments $(\boldsymbol{\bullet}, \mathbf{\square})$. The ATP $(O, \boldsymbol{O})$ and $\operatorname{GSH}(\square, \boldsymbol{\square})$ contents of the isolated cells were estimated. The ATP and GSH contents of spermatocytes freshly isolated from testicular tissue were $12.8 \pm 1.6$ and $11 \cdot 6 \pm 0 \cdot 1 \mathrm{nmol} / 10^{6}$ cells, respectively. The ATP and GSH contents of spermatids freshly isolated from testicular tissue were $3 \cdot 1 \pm 0 \cdot 1$ and $3 \cdot 7 \pm 0 \cdot 1 \mathrm{nmol} / 10^{6}$ cells, respectively. Values represent the mean \pm s.d. of triplicate incubations.

Spermatocytes and spermatids isolated from diethyl maleate-treated tubule fragments, immediately after the 2 -h treatment, had a very low GSH content compared to controls (Fig. 5). However, germ cell preparations isolated $46 \mathrm{~h}$ after the diethyl maleate treatment showed a GSH content similar to that of cells isolated from the untreated tubule fragments (Fig. 5). Furthermore, it was observed that the diethyl maleate treatment did not affect the ATP content of the germ cells isolated from the tubule fragments after different periods of incubation. The ATP content of the cells remained high and was not different from that of the cells isolated from untreated tubule fragments.

Late pachytene spermatocytes were recovered, after $72 \mathrm{~h}$ of incubation, with virtually equal purity $(>90 \%)$ and quantity from the diethyl maleate-treated and control tubule fragments. The number of spermatids recovered after $72 \mathrm{~h}$ was low and the purity was $\sim 50 \%$. The other $50 \%$ of 
the cells in these spermatid preparations were mainly early primary spermatocytes. The germ cells recovered from the tubule fragments were resistant to trypsin and DNAase treatment, and were selected according to size and density. This, and also the ATP content of the cells, demonstrates that viable cells were recovered.

\section{Discussion}

In this study of the possible role of Sertoli cells in glutathione metabolism of spermatocytes and spermatids, the main approach was to evoke GSH depletion of isolated spermatogenic cells and tubule fragments and to estimate the recovery of the cellular GSH pool. Two methods were used to lower the glutathione levels. First, glutathione synthesis was inhibited using buthionine sulphoximine (BSO) (Griffith \& Meister, 1979; Griffith, 1981), which is a specific inhibitor of $\gamma$-glutamylcysteine synthetase (EC 6.3.2.2). Second, the cells were incubated with a substrate for glutathione S-transferase (GST). This enzyme catalyses the conjugation between GSH and electrophilic compounds. The $\alpha, \beta$-unsaturated diester diethyl maleate is a suitable GST substrate and can be used to decrease the GSH level in intact animals via a GST-catalysed conjugation reaction (Allameh et al., 1987). This compound can also be used to cause GSH depletion of cultured cells, including Chinese hamster ovary cells (Mitchell et al., 1983; Rice et al., 1986), human lung carcinoma cells (Brodie \& Reed, 1985) and round spermatids from rats (Den Boer et al., 1988), and was used in the present experiments to deplete the GSH pool of isolated spermatogenic cells, cultured Sertoli cells and tubule fragments from hamsters.

In isolated spermatocytes and spermatids from hamsters, a gradual decrease of the GSH content was observed during prolonged incubation. Under control incubation conditions this diminution did not lead to a concomitant loss of the viability of the cells, as indicated by the maintenance of the cellular ATP content. The decrease of the GSH content could reflect a low rate of GSH synthesis, relative to the rate of GSH expenditure. The synthesis of GSH in the germ cells may require exogenous compounds, but addition of glycine, cysteine and glutamate, or glutathione to the incubations did not prevent the gradual loss of cellular GSH. Furthermore, the GSH content of isolated spermatids was also not elevated using the compound L-2-oxothiazolidine-4carboxylate, an oxoproline analogue which serves as a cysteine delivery system and can cause an increase of the GSH level of lymphocytes (Williamson et al., 1982; Fidelus et al., 1987).

The gradual loss of GSH from the isolated germ cells is not explained by a complete absence of GSH synthesis in these cells. The isolated spermatocytes and spermatids appear to have a limited capacity to synthesize GSH. This is indicated by the observation that the decrease of the GSH pool was slightly accelerated during incubation of the cells in the presence of $50 \mu \mathrm{M}-\mathrm{BSO}$. This effect on the cellular GSH content was not caused by a non-specific toxic effect of BSO, since the ATP content of isolated spermatids remained high after incubation in the presence of much higher BSO concentrations, up to $4 \mathrm{~mm}$. The time-course of the BSO-induced depletion of GSH in spermatocytes and spermatids showed that the cellular GSH content was decreased only approximately $50 \%$ after $24 \mathrm{~h}$ of incubation.

It is not clear which biochemical processes determine the loss of GSH from the isolated spermatogenic cells. GSH can be used as an intracellular source of cysteine for incorporation into proteins. Another process may involve the export from the cells of GSH-related compounds, including oxidized glutathione (GSSG), GSH mixed disulphides, and GSH-conjugates (Meister \& Anderson, 1983). Obviously, this latter mechanism of utilization of GSH is important for GSH-supported defence mechanisms.

Exposure of isolated rat spermatids to GST substrates leads to cellular GSH depletion as a result of the formation of conjugates (Den Boer et al., 1988). This mechanism was used in the present experiments to deplete the GSH pool of isolated hamster spermatocytes and spermatids, by incubating the cells in the presence of diethyl maleate. This treatment did not affect the viability of 
the cells, as indicated by the high ATP contents of the spermatogenic cells. With respect to the present discussion on GSH synthesis, it should be emphasized that isolated GSH-depleted spermatids did not recover their GSH content during prolonged incubation under different conditions (see 'Results').

Cultured Sertoli cells from immature hamsters have an active GSH synthesis system, as indicated by the recovery of the GSH pool after diethyl maleate-induced depletion, which was prevented by addition of BSO to the medium. We examined whether GSH synthesis in spermatogenic cells is dependent on the presence of Sertoli cells. A possible action of Sertoli cells on GSH synthesis in germ cells may not be exerted by a soluble factor. This is indicated by the observation that there was no effect of Sertoli cell-conditioned medium or Sertoli cell-germ cell co-culture on the GSH content of control and diethyl maleate-treated spermatids during $48 \mathrm{~h}$ of incubation (not shown). A possible role of Sertoli cells, however, was indicated in experiments using tubule fragments. In these experiments a preincubation period of $24 \mathrm{~h}$ was included to allow the tubule fragments to attach to the plastic surface of the culture wells or flasks. During this 24 -h period there was a marked decrease of the GSH pool of the tubule fragments, which may reflect a decrease of the GSH content of the spermatogenic cells, rather than a loss of spermatogenic cells, for the following reasons. Cultured Sertoli cells showed a GSH content of $10 \mathrm{nmol} / \mathrm{mg}$ protein, whereas spermatids and spermatocytes contained 30 and $40 \mathrm{nmol} \mathrm{GSH} / \mathrm{mg}$ protein. These approximate values indicate that most of the GSH in tubular fragments is present in the germ cells. Spermatids and spermatocytes isolated from the preincubated tubule fragments showed a GSH content which was $50 \%$ lower than that of germ cells freshly isolated from testicular tissue. The cause of this initial rapid decrease of the GSH pool is not known.

The indication for a role of Sertoli cells in germ-cell GSH synthesis was obtained by diethyl maleate treatment of the preincubated tubule fragments. The GSH depletion of the tubule fragments induced by the diethyl maleate treatment corresponded with a GSH depletion of the germ cells present within the fragments, down to a content of less than $10 \%$ of the controls. The subsequent recovery of the GSH content of the tubule fragments after removal of the diethyl maleate also corresponded with a recovery of the GSH content of the spermatogenic cells enclosed in the tubule fragments, up to control levels (a 10-fold increase). As discussed above, such a recovery of the GSH pool was not observed for diethyl maleate-treated isolated spermatocytes and spermatids.

From these observations, it can be suggested that germ cells in tubule fragments can synthesize GSH at a sufficiently high rate to recover from GSH depletion, whereas isolated germ cells may have a much lower rate of GSH synthesis. This points to a role of Sertoli cells in GSH synthesis by the germ cells. This aspect of Sertoli cell function might involve intercellular transport of amino acids, or a more direct stimulatory effect on GSH biosynthesis through an unknown mechanism.

The membrane-bound enzyme $\gamma$-glutamyl transpeptidase (GGT; EC 2.3.2.2) is possibly involved in GSH synthesis through its function in the uptake of amino acids. The enzyme is thought to transfer the $\gamma$-glutamyl group of extracellular GSH to an extracellular amino acid. The $\gamma$-glutamyl amino acid is then transported into the cell (Meister \& Anderson, 1983). The enzyme activity may be a rate-limiting factor in transport of a number of amino acids, including cysteine, and the maintenance of cellular glutathione levels. High activities of this enzyme are present in Sertoli cells, and the activity of the enzyme increases during post-natal testicular development (Lu \& Steinberger, 1977). The activity of GGT in isolated spermatids is low (Lu \& Steinberger, 1977), but this needs to be confirmed using a germ cell isolation procedure which does not include enzyme treatments, since GGT activities can be removed from cell surfaces by proteolytic enzymes (Meister et al., 1981). If indeed the GGT activity of germ cells in situ is low, the germ cells may take up $\gamma$-glutamyl amino acids produced by Sertoli cells.

The present results indicate that cell-to-cell interaction may be important for the role of Sertoli cells in glutathione synthesis in spermatogenic cells. The biochemical mechanism of this interaction, however, remains to be clarified. 
This investigation received financial support from the World Health Organization Special Programme of Research, Development and Research Training in Human Reproduction (project 87079).

\section{References}

Allameh, A., Saxena, M., Mehta, L.N. \& Raj, H.G. (1987) Comparison of pulmonary and hepatic glutathione depletion by diethyl maleate. Med. Sci. Res. 15, 957-958.

Bradford, M.M. (1976) A rapid and sensitive method for the quantitation of microgram quantities of protein utilizing the principle of protein-dye binding. Analyt. Biochem. 72, 248-254.

Brodie, A.E. \& Reed, D.J. (1985) Buthionine sulfoximine of cystine uptake and glutathione biosynthesis in human lung carcinoma cells. Toxicol.appl. Pharmacol. 77, 381-387.

Calvin, H.I. \& Turner, S.I. (1982) High levels of glutathione attained during postnatal development of rat testis. J. exp. Zool. 219, 389-393.

Calvin, H.I., Medvedovsky, C. \& Worgul, B.V. (1986) Near-total glutathione depletion and age-specific cataracts induced by buthionine sulfoximine in mice. Science, NY 233, 553-555.

Den Boer, P.J. \& Grootegoed, J.A. (1988a) Mechanism of action of $(-)$ gossypol on ATP production in isolated hamster spermatids. J. Reprod. Fert. 83, 693-700.

Den Boer, P.J. \& Grootegoed, J.A. (1988b) Differential effects of $(+)$ - and (-)-gossypol enantiomers on $\mathrm{LDH}_{-} \mathrm{C}_{4}$ activity of hamster spermatogenic epithelium in vitro. J. Reprod. Fert. 83, 701-709.

Den Boer, P.J., Verkerk, A. \& Grootegoed, J.A. (1988) Effect of xenobiotics on glutathione and ATP levels in isolated round spermatids from rats. In The Molecular and Cellular Endocrinology of the Testis, pp. 241-246. Eds B. A. Cooke \& R. M. Sharpe. Raven Press, New York.

Fidelus, R.K., Ginouves, P., Lawrence, D. \& Tsan, M.-F. (1987) Modulation of intracellular glutathione concentrations alters lymphocyte activation and proliferation. Expl Cell Res. 170, 269-275.

Galdieri, M., Ziparo, E., Palombi, F., Russo, M.A. \& Stefanini, M. (198I) Pure Sertoli cell cultures: a new model for the study of somatic-germ cell interactions. J. Androl. 5, 249-254.

Griffith, O.W. (1981) Depletion of glutathione by inhibition of biosynthesis. In Methods of Enzymology, vol. 77, pp. 59-63. Ed. B. Jakoby. Academic Press, New York.

Griffith, O.W. \& Meister, A. (1979) Potent and specific inhibition of glutathione synthesis by buthionine sulfoximine (S-n-butyl homocysteine sulfoximine). $J$. biol. Chem. 254, 7558-7560.

Grootegoed, J.A., Jansen, R. \& van der Molen, H.J. (1984) The role of glucose, pyruvate and lactate in ATP production by rat spermatocytes and spermatids. Biochim. Biophys. Acta 767, 248-256.

Grootegoed, J.A., Jensen, R. \& van der Molen, H.J. (1985) Intercellular pathway of leucine catabolism in rat spermatogenic epithelium. Biochem. J. 226, 889-892.

Grosshans, K. \& Calvin, H.I. (1985) Estimation of glutathione in purified populations of mouse testis germ cells. Biol. Reprod. 33, 1197-1205.

Hissin, P.J. \& Hilf, R. (1976) A fluorometric method for determination of oxidized and reduced glutathione in tissues. Analyt. Biochem. 74, 214-226.

Ketterer, B. (1986) Detoxication reactions of glutathione and glutathione transferases. Xenobiotica 16, 957-973.

Lu, C. \& Steinberger, A. (1977) Gamma-glutamyl transpeptidase activity in the developing rat testis. Enzyme localization in isolated cell types. Biol. Reprod. 17, 84-88.

Meister, A. \& Anderson, M.E. (1983) Glutathione. Ann. Rev. Biochem. 52, $711-760$.

Meister, A., Tate, S.S. \& Griffith, O.W. (1981) $\gamma$ Glutamyl transpeptidase. In Methods of Enzymology, vol. 77, pp. 237-253. Ed. B. Jakoby. Academic Press, New York.

Mitchell, J.B., Russo, A., Biaglow, J.E. \& McPherson, S. (1983) Cellular glutathione depletion by diethyl maleate or buthionine sulfoximine: no effect of glutathione depletion on the oxygen enhancement ratio. Radiation Res. 96, $422-428$.

Oonk, R.B., Grootegoed, J.A. \& van der Molen, H.J. (1985) Comparison of the effects of insulin and follitropin on glucose metabolism by Sertoli cells from immature rats. Molec. cell. Endocrinol. 42, 39-48.

Rice, G.C., Bump, E.A., Shrieve, D.C., Lee, W. \& Kovacs, M. (1986) Quantitative analysis of cellular glutathione by flow cytometry utilizing monochlorobimane: some applications to radiation and drug resistance in vitro and in vivo. Cancer Res. 46, $6105-6110$.

Teaf, C.M., Bishop, J.B. \& Harbison, R.D. (1987) Depression of glutathione in male reproductive tissues and potentiation of EMS-induced germ cell mutagenesis by L-buthionine sulfoximine. Teratogenesis, Carcinogenesis, and Mutagenesis 7, 497-513.

Williamson, J.M., Boettcher, B. \& Meister, A. (1982) Intracellular cysteine delivery system that protects against toxicity by promoting glutathione synthesis. Proc. natn. Acad. Sci. USA 79, 6246-6249.

Received 7 March 1989 